\title{
Nebulisers for patients with HIV infection and AIDS
}

\author{
R F Miller, M J O’Doherty
}

When nebulisers are used for HIV positive patients and those with AIDS they should, where possible, be used away from other immunosuppressed or immunocompetent patients and health care workers because of the patients and health care workers because of the
risk of droplet spread (by cough) of Mycobacterium tuberculosis and other opportunistic infections.

If nebulisers are to be used within the hospital then nebulisation should be carried out in a room separate from the main ward area, ideally with a separate air extraction system. If nebulisers are to be use hylactic inhalation of pentamidine then, alternatively, patients could be taught how to do this themselves or with the help of a partner at home and appropriate resources should be invested in providing home nebulisers and compressors. Indications for the use of nebulisers in patients with HIV infection and AIDS are shown in table 1 .

Nebulised pentamidine for prophylaxis of Pneumocystis carinii pneumonia

INDICATIONS

Primary prophylaxis is indicated if an HIV positive patient has either a CD4 (T helper) cell count of $<200 / \mathrm{mm}^{3}$ (normal range 350-2200/ $\mathrm{mm}^{3}$ ) or a CD4:total lymphocyte count ratio below $1: 5 ;^{2}$ or oral thrush or unexplained fever regardless of CD4 count; ${ }^{34}$ or an alternative AIDS defining diagnosis - for example, on the basis of cerebral toxoplasmosis or cutaneous Kaposi's sarcoma regardless of CD4 count. Secondary prophylaxis should be started after an episode of $P$ carinii pneumonia.

Oral co-trimoxazole $960 \mathrm{mg}$ once daily is more effective primary and secondary prophylaxis than nebulised pentamidine and should be tried first. ${ }^{56}$ Most patients tolerate this medication (the main adverse reaction is rash which occurs in approximately $20 \%$ of patients). In patients intolerant of co-trimoxazole, dapsone (50 mg daily) and pyrmethamine (50 mg per week) should be pyras second line therapy, ${ }^{7}$ the main side effects

Table 1 Indications for use of nebulisers in patients with

(1) Prophylaxis of Pneumocystis carinii pneumonia Primary: before first episode/to prevent first episode econdary: after first episode/to prevent subsequent episodes Hospital, Canterbury, Kent, UK Correspondence to: being nausea and rash. Nebulised pentamidine should be offered to those who are intolerant of co-trimoxazole and dapsone/pyrimethamine.

CHOICE OF NEBULISER

The choice of nebuliser and delivery system is dictated by the need to deposit pentamidine in the alveoli and to avoid deposition in the oropharynx, trachea, and major bronchi. Unlike bronchodilators, nebulised pentamidine produces significant local adverse reactions if it deposits in the upper airways, including hypersalivation, a metallic or bitter taste, nausea, cough, dyspnoea, and bronchoconstriction. ${ }^{8-10}$ This makes conventional jet nebulisers inappropriate as they produce droplets of many sizes, some of which deposit in the upper respiratory tract. systems have been shown, in prospective clinical studies, to deposit adequate quantities of pentamidine in the alveoli and so afford effective prophylaxis. $^{56}$

Respirgard II

This is a jet nebuliser which has a series of internal baffles which limit the passage of large droplets into the aerosol and so reduce the frequency of adverse reactions. It also has a filter on the exhalation limb which reduces environmental contamination. The aerosol characteristics (measured with a laser beam diffraction particle sizer) are mass median aerodynamic diameter $(\mathrm{MMAD})=0.8 \mu \mathrm{m}$, geometric standard deviation $(\mathrm{GSD})=1.5 .^{8}$ The benefit in terms of a small droplet sized aerosol is achieved at the cost of a very low mass output ( $<5 \%$ of the output from a conventional nebuliser used for bronchodilator ${ }^{11}$ ) so a large nebuliser used for bronchodilators ") so a large diluted in $6 \mathrm{~m}$ of water, is loaded into the system and given as prophylaxis once a month. ${ }^{5}$

The system is driven by air or oxygen from a wall supply at $6-81 / \mathrm{min}$ or is driven by a compressor. When choosing a compressor it is important to use one that is sufficiently powerful to drive the nebuliser and has a "continuous rating" - that is, output does not vary.

Its advantages are that it has been widely used and there are the most data about it. ${ }^{5}$ Giving the same or higher doses at increased frequency using this system confers no additional protection. Its disadvantage is that it is a single use system and cannot be rinsed out and reused by the same patient. 
System 22 Mizer

This is a jet nebuliser with a higher mass output than the Respirgard II, but as the aerosol it generates is larger $(\mathrm{MMAD}=5 \mu \mathrm{m})$ there is a higher rate of adverse reactions from upper airways and oropharyngeal deposition of penairways and oropharyngeal deposition of pen-
tamidine. ${ }^{9}$ The dose of pentamidine for prophylaxis with this system is $150 \mathrm{mg}$ once per month.

The adverse reactions can be decreased by using the System 22 Mizer with an Optimist adapter which reduces the MMAD. The intrapulmonary deposition of pentamidine is equipulmonary deposition of pentar valent to that with the Respirgard II nebuliser.
The system is driven by air or oxygen, or by a continuously rated compressor. Its advantages are that the cost of the nebuliser is less than the Respirgard II and the system can be washed out and reused by the same patient. Its disadvantages are the higher adverse reaction profile which may mean that some patients are intolerant of pentamidine and require transfer to the Respirgard II system.

FisoNeb

This is a small hand held ultrasonic nebuliser which produces an aerosol of MMAD $5.2 \mu \mathrm{m}$ and, when loaded with $300 \mathrm{mg}$ pentamidine, produces equivalent intrapulmonary deposition to a Respirgard II system. However, at this dose the likelihood of adverse reactions of cough, etc is high. In clinical use a dose of $600 \mathrm{mg}$ pentamidine is used once every two weeks. ${ }^{12}$ Its advantages are that it is a small quiet system which is easily cleaned and is reusable. Its disadvantages are the higher rate of adverse reactions at doses producing equivalent deposition to the Respirgard II system. It does not contain a filter and so there is a greater likelihood of environmental contamination with exhaled pentamidine; approximately $9 \%$ of the pentamidine placed in the nebuliser escapes into the environment. ${ }^{13}$ Other ultrasonic nebulisers are not used for nebulisation of pentamidine as they are associated with excessive coughing and lower pulmonary deposition. ${ }^{14}$

\section{General recommendations}

Patients using pentamidine should be advised not to smoke cigarettes for at least two hours before nebulisation in order to reduce the likelihood of cough. Nebulised pentamidine should be used with caution in patients with asthma. It may produce a fall in the peak expiratory flow rate (PEFR) and forced expiratory volume in one second $\left(\mathrm{FEV}_{1}\right)$ even in those without a history of asthma. ${ }^{915}$ These falls in ventilatory capacity due to bronchoconstriction can be prevented by pretreating patients with bronchodilators. ${ }^{915} 16$ Nebulised terbutaline $(10 \mathrm{mg})$ or salbutamol $(5 \mathrm{mg})$ given 20 minutes before nebulised pentamidine are effective. ${ }^{15}$ Most centres, however, reserve nebulised prophylactic bronchodilators for patients known to be asthmatic, and give in all other cases $200 \mu \mathrm{g}$ salbutamol or $500 \mu \mathrm{g}$ terbutaline via a metered dose inhaler 10-15 minutes before the pentamidine. The metallic taste and hypersalivation can be minimised if the patient keeps the nebuliser mouthpiece in the mouth throughout nebulisation and does not remove it to speak; this will also reduce environmental contamination.

\section{Health care workers}

Environmental contamination is thought to have caused a number of adverse reactions in health care workers administering or supervising pentamidine nebulisation. ${ }^{17-19}$ These have included cough, bronchoconstriction, circumoral paraesthesiae, a metallic taste in the mouth, ${ }^{1718}$ and progressive reductions of gas transfer factor, ${ }^{19}$ although this last observation has not been confirmed by other groups. ${ }^{20}$

Nebulisers with exhalation filters such as the Respirgard II system are less likely to produce environmental contamination than ultrasonic nebulisers. ${ }^{13}$

Nebulisation of pentamidine in hospital or outpatient facilities must be carried out in a room separate from other patients, ideally with its own extraction ventilation system. If nebulisation is supervised the health care worker (nurse, physiotherapist) should prepare the nebuliser, load it with pentamidine, and start the compressor (or switch on the air supply), and then leave the room immediately, not returning until nebulisation is complete. The patient can be instructed to switch off the air supply or compressor, either if they experience problems or at completion of nebulisation. If these guidelines are followed the likelihood of adverse reactions in health care workers is markedly reduced. ${ }^{17}$

\section{Treatment of Pneumocystis carinii}

pneumonia

Nebulised pentamidine is effective for mild to moderate severity pneumocystis pneumonia 481421 but is other more effective therapies are available such as oral co-trimoxazole, clindamycin with primaquine, or atovaquone. If nebulised pentamidine is used as treatment it is suggested that it is combined with intravenous pentamidine ( $4 \mathrm{mg} / \mathrm{kg}$ once daily) for the first 3-5 days to ensure that intrapulmonary accumulation of the drug occurs rapidly, and the likelihood Studies have used the Re and either $600 \mathrm{mg}$ pentaride and either $600 \mathrm{mg}$ pentamidine $\mathrm{e}^{2022}$ or a dose of $8 \mathrm{mg} / \mathrm{kg}$ given once daily for 21 days.

As higher doses of pentamidine are used than for prophylaxis the potential for adverse reactions is higher. ${ }^{8}$ Patients again should be advised to avoid cigarette smoking and a nebugiven routinely 20 minutes before nebulised pentamidine. It is important to obtain alveolar deposition of the drug. Although the Respirgard II is the system that has been licensed in the US by the FDA for delivery of nebulised pentamidine as treatment or prophylaxis, any nebuliser with a is acceptable. However, no other syste 
been evaluated in clinical studies in patients with mild to moderately severe pneumocystis pneumonia.

It is important to note that there is a very slow clinical response to treatment and it may take from 10 days to two weeks before there is a reduction in fever and any appreciable improvement in the chest radiograph. ${ }^{8}$ There are also concerns that this form of therapy, if used to treat pneumocystis pneumonia, may fail to suppress extrapulmonary dissemination of $P$ carinii. $^{23}$ There is also a higher relapse rate following successful treatment with nebulised pentamidine than following treatment with cotrimoxazole. $^{24}$

\section{Sputum induction}

This technique has evolved for the non-invasive diagnosis of respiratory infections such as $P$ carinii and other bacterial pneumonias in immunosuppressed patients. As most HIV positive patients with respiratory problems do not itive patients with respiratory problems do not
spontaneously expectorate sputum, sputum induction enables deep cough specimens to be obtained. The patient inhales an aerosol of hypertonic $(2.7 \%=3 \mathrm{~N})$ saline which deposits in peripheral airways and alveoli. This induces a serous response and, because it is hyperosmolar, it draws fluid from the lung interstitium into the alveoli where inflammatory casts and debris are loosened and can move via the mucociliary escalator to the central airways. The aerosol induces cough. ${ }^{25}$

Overall the sensitivity of this technique for diagnosis of $P$ carinii and other pathogens is less than that from bronchoscopy with bronchoalveolar lavage. ${ }^{25}$ The technique is likely to be more successful if dedicated personnel such as a staff nurse or physiotherapist are trained in the technique..$^{25}$ The yield for $P$ carinii from sputum induction is more likely to be successful if there is a high local prevalence of pneumocystis. ${ }^{26}$

Careful attention to detail is required if the technique is to be successful. Patients do not need to starve overnight but they should avoid eating in the two hours or so beforehand. If they have false teeth these should be removed. Rigorous oral cleansing with tap water and a single use new toothbrush is necessary to clean debris from between the teeth, the buccal membranes, and the tongue. (Food and squamous cells may take up stain and so obscure $P$ carinii and other pathogens.) Another reason for avoiding eating just before the procedure is that in some patients it can induce nausea and retching. ${ }^{24}$

A high output ultrasonic nebuliser - for example, the UltraNeb $99 \mathrm{~m}$ (DeVilbiss) or DP100 (DP Medical) - should be used as they enable $20-30 \mathrm{ml}$ of hypertonic saline to be nebulised over 15-20 minutes. Close laboratory collaboration is necessary. It is important to assess the adequacy of the specimen obtained - for example, with Papanicolaou stain to check for the presence of alveolar macrophages confirming that the specimen originates from the lower respiratory tract. Samples of induced sputum look clear and are colourless and may mimic saliva; they may be thrown away mistakenly by the laboratory and not analysed..$^{25}$ The technique of sputum induction is safe and requires no special supervision but in some patients nausea and retching may occur (probpatients nausea and retching may occur ( ably secondary to swallowing hypertonic saline) ${ }^{25}$ Other patients become dyspnoeic and in some bronchoconstriction occurs. Some patients have unpredictable arterial desaturation during the procedure and this may persist after the procedure has finished. ${ }^{27}$ This desaturation is not related to the baseline arterial saturation and may occur without asterial sociated dyspnoea. Arterial oxygen saturation$\left(\mathrm{S}_{2}\right)$ dyould be Arterial oxygen saturation $\left(\mathrm{SaO}_{2}\right)$ should be monitored with a transcutaneous oximeter throughout the procedure. In addition, care should be taken if other procedures such as exercise testing are performed immediately after sputum induction because of the risk of persistent desaturation. ${ }^{27}$

\section{Bronchodilator therapy}

No special equipment is necessary. The same codicils apply to the use of nebulisers - that is, where possible these should be used away from other immunosuppressed patients because of the risk of nosocomial transmission of tuberculosis and other infections. ${ }^{1}$

\section{Nuclear medicine ventilation scanning}

In all ventilation procedures involving radionuclides a closed system should be used. In HIV positive patients and those with AIDS (or those perceived to be "at risk") single patient use circuits are recommended. The Medic-Aid and Amersham circuits are appropriate.

\section{Equipment}

AIR-JET NEBULISERS FOR INHALED PENTAMIDINE (a) Respirgard II (Marquest): UK supplier: AAH Medical, Unit 20, Broombank Business Park, Broombank Road, Sheepsbridge, Chesterfield S41 9Q5. Telephone: 01246451501. (b) System 22 "Mizer" (Medic-Aid): MedicAid Ltd, Heath Place, Bognor Regis, Sussex, PO22 9SL. Telephone: 01243267616.

ULTRASONIC NEBULISERS FOR INHALED

PENTAMIDINE

(a) FisoNeb (Fisons): Fisons plc, Coleorton Hall, Ashby Road, Coleorton, Coalville, Leicestershire LE67 8GP. Telephone: 01509 634000.

HIGH OUTPUT ULTRASONIC NEBULISERS FOR SPUTUM INDUCTION

(a) UltraNeb 99m (DeVilbiss): DeVilbiss Health Care UK Ltd, Airlinks, Spitfire Way, Heston, Middlesex TW5 9MR. Telephone: 01817561133

(b) DP100 (DP Medical): Meylan, France.

VENTILATION CIRCUITS FOR NUCLEAR MEDICINE

(a) Medic-Aid: as above. 
(b) Amersham: Amersham Health Care, Amersham Place, Little Chalfont, Buckinghamshire HP7 9NA. Telephone: 01494544000.

1 Nardell EA. Dodging droplet nuclei: reducing the probability of nosocomial tuberculosis transmission in the
AIDS era. Am Rev Respir Dis 1990;142:501-3. 2 Masur H, Ognibene FP, Yarchoan R, Shelhamer JH, Baird $\mathrm{BF}$, Travis $\mathrm{W}$, et al. $\mathrm{CD} 4$ counts as predictors of op-
portunistic pneumonias in human immunodeficiency (HIV) infection. Ann Intern Med 1989;111:223-31. Phair J, Munoz A, Laslow R, Rinaldo CR, Saah A, et al. The risk of Pneumocystis carinii pneumonia among men
infected with human immunodeficiency virus type $1 . N$ Engl f Med 1990;322:161-5.

4 Miller RF. Prevention and treatment of Pneumocystis carinii
pneumonia in patients infected with HIV. Drug Therap

Hardy WDD, Finberg J, Finkelstein DM, Detels R, Power
ME, He W, Kaczkac C, et al. A controlled trial of tri-

$\mathrm{ME}, \mathrm{He} \mathrm{W}$, Kaczkac C, $e t$ al. A controlled trial of tri-
methoprim-sulfamethoxazole or aerosolised pentamidine for secondary prophylaxis of Pneumocystis carinii pneumonia in patients with the acquired immunodeficiency
syndrome. N Engl f Med 1992;327:1842-8.

syndrome. N Engl f Med 1992;327:1842-8.
6 Schneider MME, Hoepelman AM, Efftinck Shattenkerk

JKM, Nielson TI, Van der Graafy, Frissen JPHJ, et al. A controlled trial of aerosolised pentamidine or tri-
methoprim-sulfamethoxazole as primary prophylaxis methoprim-sulfamethoxazole as primary prophylaxis
against Pneumocystis carinii pneumonia in patients with human immunodeficiency virus infection. N Engl f Med 1992;327:1836-41. AG, Jelazko P, et al. Dapsone-pyrimethamine compared with aerosolized pentamidine as primary prophylaxi
against Pneumocystis carinii pneumonia and toxoplasmosi in HIV infection. N Engl 9 Med 1993;328:1514-20. monia in the acquired immunodeficiency syndrome. Thorax 1989;44:565-9. Nunan TO, et al. Differences in relative efficiency of
nebulisers for pentamidine administration. Lancet 1988 ; nebulisers for pentamidine administration. Lancet 1988 ;
ii:1283-6. Miller R, Steel S. Nebulised pentamidine as prophylaxis for Preumocystis carinii pneumonia. 1 Ant:27:153-7.
1991
malldone GC, Perry RJ, Deutsch DG. Characteristics of 11 Smalldone GC, Perry RJ, Deutsch DG. Characteristics of
nebulisers used in the treatment of AIDS-related Pneumo-
cystis carinii pneumonia. I A Aerosol Med 1988;1:113-26.
12 Montaner JSG, Lawson LM, Gervais A, Hyland RH, Chan

CK, Falutz JM, et al. Lerosol pentamidine for secondary prophylaxis of AIDS-related Pneumocystis carinii pneu-
monia: a randomised, placebo-controlled study. Ann Intern monia: a randomised, placebo-controlled study. Ann Intern
Med 1991;14:948-53.

13 Thomas SHL, Page CM, O'Doherty MJ, Bateman NT. Thomas SHL, O'Doherty MJ, Page CJ, Nunan TO, Bate-
man NT. Which apparatus for inhaled pentamidine? A
comparison of pulmonary deposition via eight nebulisers. Eur Respir F 1991;4:616-22.
Leigh TR, Wiggins J, Gazzard B, Collins JV. A comparison of several agents with two delivery systems for the pretamidine isethionate. Respir Med 1991;85:527-31.
mith DE, Herd D, Gazzard B. Reversible bronchoSmith $\mathrm{DE}$, Herd D, Gazzard B. Reversible broncho-
constriction with nebulised pentamidine. Lancet 1988;ii: 905. sollsed pentamidine. Lancet 1989, 19 Gude JK. Selective delivery of pentamidine to the lung by 20 Camus F, de Picciotto C, Lepretre A, Landman R, Girard PM. Pulmonary tolerance of prophylactic aerolised pen-
PM pen tamidine in HIV infected patients. Chest 1991;99:609-12.
Miller RF, Mitchell DM. Pneumocystis carinii pneumonia.

22 Montax 1992,47.303-14. Th, J, Lin ET, Dabs Corkery KJ, et al. Aerosolised pentamidine as sole therapy for Pneumocystis carinii pneumonia in patients with acquired immunodeficiency syndrome. Lancet 1987;ii:
$480-2$.

23 Coker RJ, Clark D, Claydon EL, Gompels M, Ainsworth JG, Lucas SB, et al. Disseminated Pneumocystis carini
infection in AIDS. F Clin Pathol 1991;44:820-3. infection in AIDS. F Clin Pathol 1991;44:820-3.
Montgomery AB, Feeigal DW, Sattler $\mathrm{F}$. Mason GR, Ca-
tanzaro A, Edisosn R, et al. Pentamidine aerosol versus trimethoprim-sulfamethoxazole for Pneumocystis carinii in Carquired Med 1995;151:1068-74.
Cand

25 Miller RF, Kocjan G, Buckland J, Holton J, Malin A, Semple SJG, et al. Sputum induction for the diagnosis of
pulmonary disease in HIV positive patients. $\mathcal{F}$ Infect 1991;

Ch:5-15. Barre A, et al. Cost effectiveness of the induced sputum technique for the diagnosis of Pneumocystis carinii pneu-
monia (PCP) in HIV infected patients. Eur Respir $\mathcal{F} 1993$; 6:248-52.
Miller RF, Buckland J, Semple SJG. Arterial desaturation Miller RF, Buckland J, Semple SJG. Arterial desaturation
in HIV positive patients undergoing sputum induction.
Thorax 1991;46:449-51. 